\title{
Delegação e Integração Regional: Aspectos Teóricos do Paradigma Principal-Agente Aplicado ao Sistema Europeu*
}

Cinthia Regina Campos**

\section{Introdução: Situando Objeto e Teoria}

( $)$ presente artigo tem por objetivo sintetizar as principais afirmações sobre a aplicabilidade da teoria da delegação a sistemas de integração regional, bem como expor as questões atualmente discutidas no âmbito da União Europeia (UE) por aqueles pesquisadores que empregam o paradigma principal-agente (principal-agent) em suas análises. $\mathrm{O}$ estudo de processos de delegação tem sido frequente na tradição norte-americana, principalmente sobre as relações entre o

\footnotetext{
* Artigo recebido em abril e aprovado para publicação em agosto de 2008. Copidescado por Duda Costa. Este artigo faz parte da pesquisa de mestrado da autora.

** Mestranda do Programa de Pós-graduação em Ciência Política pela Universidade Federal de Pernambuco (UFPE). E-mail: cinthyacp@gmail.com.
} 
Congresso Nacional e a Casa Branca; obras como a de McCubbins e Schwartz (1984) e Epstein e O'Halloran (1999) são citações recorrentes nos trabalhos dedicados a essa temática. No entanto, o foco apresentado aqui é um pouco diferenciado dessa tradição que prioriza as relações internas entre Executivo e Legislativo.

A União Europeia é considerada a mais avançada e bem-sucedida política integracionista existente. Após cinquenta anos da assinatura do Tratado de Roma, quando se configurou a primeira imagem do que viria a ser o bloco econômico conhecido hoje, diversos mecanismos foram introduzidos por tratados posteriores com o objetivo de expandir as relações socioeconômicas entre seus membros. Os principais marcos normativos do bloco proporcionaram a criação de instituições supranacionais com a função principal de reger o sistema de forma coletiva e com um caráter pró-integração, além de estabelecerem as regras pelas quais as decisões seriam tomadas e as competências de cada instituição. Atualmente com um total de 27 membros, incorporados de forma gradativa ${ }^{1}$ ao longo dos anos, a União Europeia detém números expressivos se comparada a outros blocos econômicos, possuindo uma população em torno de 455 milhões e

\section{Tabela 1}

Lista dos Países Integrantes da União Europeia por Data de Adesão

\begin{tabular}{ll}
\hline Data de adesão & Países integrados \\
\hline Fundadores & Alemanha Ocidental, França, Itália, Bélgica Luxemburgo e \\
& Países Baixos \\
1973 & Dinamarca, Irlanda e Reino Unido \\
1981 & Grécia \\
1986 & Portugal e Espanha \\
1990 & Alemanha Oriental \\
1995 & Áustria, Finlândia e Suécia \\
2004 & República Tcheca, Estônia, Letônia, Lituana, Polônia, \\
& Eslováquia, Eslovênia, Hungria, Chipre e Malta \\
2007 & Bulgária e Romênia \\
\hline
\end{tabular}

Fonte: Europa - O portal da União Europeia. Disponível em: <http://europa.eu>. 
com PIB total de 10 bilhões de euros. A Tabela 1 informa quando se deu a incorporação dos atuais Estados-membros.

A UE divide-se em três pilares de atuação, a saber: o comunitário, referente aos assuntos de ordem comercial e administrativa; o de política externa e segurança comum; e o de cooperação policial e judicial, tendo estes dois últimos sido inseridos apenas a partir do Tratado de Maastricht, em 1992 (D’ARCY, 2002). Não existe uma definição clara na literatura disponível para o desenho institucional que o bloco hoje possui, pois o mesmo já não pode mais ser enquadrado como um simples mercado comum e, em contrapartida, não pode ser visualizado como uma união política e monetária completa. Segundo Tostes (2004), por vezes o bloco é percebido como um processo de construção de uma federação europeia, enquanto outros acadêmicos o denotam como um mero regime internacional, composto de metas e normas precisas. Porém, a autora afirma que não se pode engessar o bloco em nenhuma das duas definições, tendo em vista que o nível de integração não alcança a consistência de uma federação e ao mesmo tempo possui uma complexidade institucional deveras maior do que a de um regime internacional.

Apesar de não ser possível considerar o bloco econômico como uma espécie de Estado nos moldes modernos, a UE estrutura-se de forma semelhante, calhando às suas principais instituições decisórias as funções legislativas, executivas e de supervisão jurídica. Temos: o Conselho de Ministros, formado pelos governos nacionais, que é o principal órgão responsável pela tomada de decisão, e que também exerce as funções legislativa e executiva; o Parlamento Europeu, eleito por sufrágio universal, que fundamentalmente legisla sobre as matérias em discussão, apesar de ainda deter pouco poder decisivo na maior parte dos assuntos; a Comissão Executiva, que elabora grande parte dos atos a serem discutidos e adotados, bem como executa parte deles, sendo também formada por representantes nacionais; e, por fim, a Corte de Justiça, responsável pela solução de controvérsias. As 
competências e as relações entre essas instituições serão em breve devidamente abordadas de forma mais aprofundada.

Na última década, tem sido perceptível um interesse maior por parte dos pesquisadores da integração regional em analisar esse arcabouço institucional pelo prisma da teoria da delegação. Questiona-se não mais se é possível a transposição dessa perspectiva, comumente empregada na esfera interna estatal, para o âmbito internacional, mas como se dá tal transferência e que problemas de pesquisa se apresentam. Certamente que a discussão está apenas no início, no entanto, mostra-se fértil e produtiva. É papel do presente artigo sumarizar o debate, abordando questões como tomada de decisão, mecanismos de controle e relações interinstitucionais.

O artigo é composto de três partes principais. A primeira dedica-se a definir o termo delegação de poderes, discutir os problemas identificados pela teoria e como se dá a transposição da esfera nacional para a internacional. A segunda parte explora justamente como se dá a aplicação do paradigma principal-agente no processo de integração europeu, analisando em separado a Comissão Executiva, o Parlamento Europeu e a Corte de Justiça. Na última e não menos importante etapa do artigo, pretende-se discutir as dificuldades do paradigma em questão e os argumentos de seus defensores.

\section{Delegação de Poderes: Solução ou Problema?}

A definição do que seria delegação de poderes não é uma tarefa das mais complexas. Segundo Bendor et al. (2001), se até Deus delega, não haveria razão para, no exercício do poder, ser diferente. A delegação ocorre quando um ator detentor de poderes transfere competências a outro ator, seja órgão ou entidade, para que este exerça certas funções determinadas pelo primeiro. Dessa forma, temos o principal, aquele que delega funções e poderes, e o agente, 


\section{Delegação e Integração Regional: Aspectos}

Teóricos do Paradigma Principal-Agente...

aquele que os exerce. Ainda segundo os autores, as limitações dos líderes governamentais têm sido a principal razão para o aumento da delegação na gestão pública. Lupia (2001, p. 2) ${ }^{2}$ afirma:

Delegação ocorre quando algumas pessoas pedem a outras que realizem tarefas a seu favor. Para a maioria de nós, delegação é uma parte importante da vida diária. Nós delegamos aos comerciantes a tarefa de adquirir vários produtos alimentícios, nós delegamos aos doutores a tarefa de reparar ossos quebrados, e nós delegamos às agências de notícias a tarefa de nos informar dos eventos locais e mundiais. A delegação é benéfica, porque podemos utilizá-la para cobrir limitações pessoais. Esse benefício é importante porque cada um de nós tem limites de tempo, energia e talento. Quando as pessoas para quem nós delegamos devotam seu tempo, energia e talento para nossas necessidades, a delegação aumenta o número de tarefas que nós podemos executar.

Em suma, a redução dos custos na tomada de decisão e na execução de tarefas permite ao principal gerir melhor outras de suas competências, que, na ausência de um agente, seriam inviáveis. Dito isso, claro está que o agente trabalha, idealmente, para o interesse do principal (MAJONE, 2001). No entanto, reside aqui o maior problema: quando o agente trabalha apenas para seu próprio interesse. Segundo Bendor et al. (2001), assim como o principal pode delegar certas competências e outras não, o agente pode trabalhar ou não pelo principal: "se, ao agente, é delegada autoridade, então ele tem uma oportunidade para adquirir informação antes que escolha uma ação, enquanto o principal deve decidir em face da incerteza" (BENDOR et al., 2001, p. 240). Lupia (2001) afirma que, para evitar o que ele denomina de agency loss, a perda da agência, ou o principal e o agente devem ter os mesmos interesses, ou o principal deve ter amplo conhecimento sobre as ações do agente a ponto de perceber se 
determinada ação executada é ou não do seu interesse. Em ambos os casos, são notórios a alta incerteza sobre as preferências de cada um, principal-agente, e até que ponto o primeiro tem acesso suficiente às informações sobre o desempenho de seu agente. De fato, se lhe fosse possível despender tempo e talento para monitorar em detalhe as tarefas por ele delegadas, a própria delegação já não teria senso lógico.

Baseados na teoria dos jogos, Bendor et al. (2001) identificam ainda dois jogos possíveis para o ato de delegação e que poderiam diminuir a possibilidade de uma ação oportunista por parte do agente: 1) o principal decide quando delegar autoridade ou não a um agente independentemente de este repassar as informações obtidas (delegationof-authority game); 2) o agente detém diferentes tipos de autoridade, seja para acumular informações, seja para elaborar propostas; no entanto, ele perde o poder de tomar decisões, apenas o principal o possui (signaling game). Eles ainda fazem algumas ponderações, afirmando que, no primeiro caso, o principal tende a escolher um agente próximo a seus interesses, atingindo assim um único equilíbrio. Em relação ao signaling game, é necessário perceber quantitativamente e qualitativamente as informações que foram transferidas ao principal, pois, se este tiver interesses adversos, pode obstruir a tomada de decisão. Os autores apontam que apenas a delegação em contextos repetidos pode diminuir o abismo existente entre o que é racional individualmente e o que é ótimo coletivamente. No entanto, eles mesmos evidenciam a fragilidade desta percepção: "No mundo real, pessoas retiram-se ou morrem, então ninguém joga infinitamente um jogo repetido" (BENDOR et al., 2001, p. 257).

James Wilson (1989) em obra seminal, intitulada Bureaucracy, trata do desempenho das agências governamentais e de como o Executivo tenta gerenciar esse sistema de delegação em proveito de seus próprios interesses. Segundo ele, há três problemas que vão além do paradigma principal-agente e contribuem para que o agente não 
trabalhe em prol do seu principal. O primeiro deles é quando o output (trabalho) de uma agência não apenas é não observável, mas quando simplesmente sequer é conhecido. Dessa forma, o principal não tem informação sobre o outcome (resultado) que a agência obtém, não sabendo como administrar qualquer problema que exista e muito menos julgar o trabalho do agente após sua execução. A segunda dificuldade é numérica e temporal: o agente, percebido como ator unitário em uma perspectiva governamental, provavelmente tem vários principals $^{3}$ que são frequentemente substituídos nas eleições. Nesse caso, os interesses entre principal e agente são constantemente modificados, o que aumenta as oportunidades para o agente trabalhar em interesse próprio. Por fim, assim como o principal, o agente traz consigo suas próprias preferências políticas, padrões profissionais e experiências prévias ao ato de delegação, o que também pode refletir na falta de sintonia entre os interesses do principal e do agente.

No plano internacional, problemas como esses apontados anteriormente pelos estudiosos da teoria da delegação também estão presentes. Porém, há peculiaridades que devem ser discutidas. O foco das pesquisas que tratam de delegação internacional reside na cessão de soberania ${ }^{4}$ a entidades supranacionais, compreendendo instituições como a Organização das Nações Unidas (ONU) e a Organização Mundial do Comércio (OMC), mas também incluindo organismos de menor abrangência, como é o caso europeu. Em recente ensaio, Epstein e O'Halloran (2006) afirmam que, quanto maior for a homogeneidade presente entre os membros de uma organização, maior será o poder delegado, consolidando a interação entre agente e principal.

Em contrapartida, Bradley e Kelley (2006), em uma perspectiva mais normativa, introduzem o conceito de binding authority, que corresponde ao poder delegado a uma entidade ${ }^{5}$ para que tome medidas mesmo que contrárias aos interesses individuais de um dos membros. Essa observação é pertinente, pois, no cenário internacional, 
vários principals fazem parte da relação de delegação aqui abordada. Segundo os autores - e então teríamos uma diferença significativa entre a esfera nacional e a internacional -, em uma entidade internacional coletiva, um membro individual não teria o poder de controle sobre as ações tomadas pela entidade, o que a caracterizaria como uma organização independente ${ }^{6}$ da vontade individual de seus membros. Epstein e O'Halloran (2006) discordam dessa perspectiva e não consideram o poder de veto como uma forma de evitar a delegação de soberania, mas sim como um equilíbrio do próprio sistema e da relação entre agente e principal. Eles apontam ainda que, em ambas esferas, doméstica e internacional, os Estados detêm poder de veto sobre as políticas executadas pela entidade, porém apenas no plano internacional os Estados podem se retirar do sistema. No entanto, custos da saída, regras coercitivas informais e outros mecanismos podem tornar a retirada mais convidativa ou não.

Em suma, a delegação de poderes tanto na esfera doméstica quanto na internacional proporciona benefícios e custos. No entanto, ela tem se tornado mais frequente, e por vezes necessária, tendo em vista as limitações já discutidas. O que parece ser consenso para que a delegação não falhe ou piore o status quo do principal é a necessidade deste em monitorar e implementar mecanismos de cumprimento das tarefas por ele delegadas (LAKE, 2006). Na próxima seção, fica claro como esse fenômeno se dá no âmbito europeu.

\section{Quem? Quando? Por quê? A(s) lógica(s) de delegação na União Europeía}

Na última década, tem sido crescente a inserção da escolha racional nos estudos sobre o processo de integração na União Europeia, principalmente no que se refere às pesquisas sobre sistema decisório e sobre a interação entre as instituições responsáveis pelo procedimento. 
Nesta seção do artigo, apresentam-se problemáticas teóricas e o que se tem produzido na área sobre o assunto.

Em primeira análise, é possível identificar um duplo exercício de delegação (MAJONE, 2001). O primeiro concerne aos Estadosmembros em relação às instituições europeias, configurando um processo gradual de concessão de poderes, em que coexistem dois sistemas normativos, o nacional e o supranacional, estando a cargo do mecanismo de subsidiariedade ${ }^{7}$ a função de estabelecer em que momento um se sobrepõe ao outro. $\mathrm{O}$ segundo refere-se ao poder delegado pelo Conselho, por meio dos tratados constitucionais, às instituições supranacionais, a saber a Comissão Executiva, Corte de Justiça e, em menor medida, ao Parlamento Europeu, sendo suas funções garantir uma política integracionista, evitando a inserção de interesses particularistas no processo decisório. Dessa forma, temos:

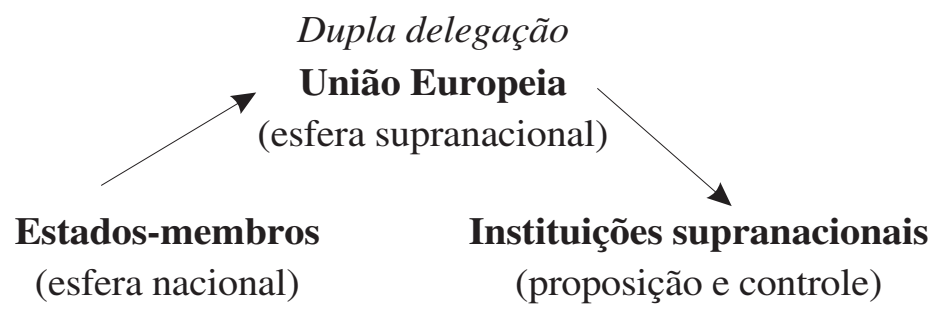

Sendo assim, na perspectiva de Majone (2001), configuram-se claramente dois tipos de delegação. $\mathrm{O}$ autor afirma que existem diversas lógicas de acordo com diferentes racionalidades para a delegação de poderes. No entanto, ele enfatiza duas possibilidades dentro da União Europeia: realçar políticas de comprometimento; e reduzir os custos da tomada de decisão. A primeira está relacionada à dificuldade em se efetivar um compromisso dos países-membros com o sistema, e isso se deve à inconsistência do tempo, em que possivelmente a política de longo prazo se difere daquela escolhida em curto prazo pelas instâncias nacionais. A segunda diz respeito à expertise 
teoricamente proporcionada pela Comissão, na medida em que suas propostas teriam um caráter mais técnico e desprovido de interesses individuais.

Para Lake (2006), o primeiro tipo de delegação apresentado por Majone $(2001)^{8}$ simplesmente não existiria, ou seja, a constituição da União Europeia não seria um ato de delegação de soberania por parte dos Estados-membros. Baseado na percepção normativa de Bradley e Kelley (2006, p. 6), ${ }^{9}$ quando um Estado delega poderes a uma entidade internacional, essa concessão pode ser irrevogável ou não, e ele pode ter o direito de observar a execução da tarefa ou não, o que não acontece em uma delegação, já que o monitoramento da ação do agente é um componente básico para o paradigma em questão. Sendo assim, Lake (2006, p. 7-8) insere a noção de pooling sovereignthy, em que

[...] Estados estão barganhando entre uma política unilateral próxima às suas preferências e uma política coletiva que é mais eficaz em localizar algum problema em comum. Em uma pooling sovereignthy dentro de uma organização internacional, Estados estão comprometendo em alguma extensão sua política ideal para atingir uma política que realmente trabalhe e solucione um problema antes deles.

A observação feita por Lake (2006) traz uma contribuição importante para a construção teórica sobre delegação internacional; porém, ao adotar a noção de binding authority, restringe o conceito de pooling sovereignthy para apenas aquelas organizações em que nenhum Estado-membro tenha o poder de obstruir a adoção de uma política que possivelmente o prejudique. ${ }^{10}$ Se essa fosse uma prática recorrente na política, a delegação simplesmente não existiria em nível supranacional e não haveria um interesse tão forte nos últimos anos sobre essa temática; o paradigma principal-agente não teria qualquer lógica em uma perspectiva global. 
Partindo para outro cenário, Pollack (1999) não questiona como se daria a delegação internacional, mas o porquê de Estados-membros delegarem poder a instituições supranacionais, como a Comissão, a Corte de Justiça e o Parlamento. Dentro do paradigma principalagente, Pollack (1999, p. 2) identifica quatro razões para que a delegação ocorra:

i. Monitorar obediência dos Estados-membros às obrigações dispostas no tratado: "em um contexto de ação coletiva e sobre informação imperfeita, agentes supranacionais podem monitorar a obediência e prover informação a todos os participantes" (POLLACK, 1999, p. 2);

ii. Solução de controvérsias legais: uma corte teria a função de julgar disputas contratuais que ocorram tanto por má informação das partes, quanto por falta de clareza do próprio tratado. "Se considerarmos tratados internacionais como um contrato, nós podemos dizer que as partes do tratado (Estados-membros) se comprometem no contrato a se comportar em certos moldes no futuro. [...] seria impossível (ou pelo menos custoso) explicar em detalhes as obrigações precisas de todas as partes durante a existência do contrato" (POLLACK, 1999, p. 2);

iii. Credibilidade: certos assuntos requerem uma tecnicidade e um entendimento que por vezes grande parte dos Estados-membros não possuem, forçando a constituição de um agente regulador e independente que apresente uma proposta complexa, mas que beneficie em alguma medida a todos os membros.

iv. Poder de iniciativa: em um sistema majoritário, faz-se necessário um agente que detenha o poder de iniciar uma proposta baseada nas considerações de todos os membros da organização e que, ao mesmo tempo, não faça parte desta.

O estudo da delegação para agências supranacionais tem sido o foco na literatura pesquisada, em virtude da própria conexão existente entre as duas lógicas de delegação, a nacional e a supranacional. Isso se 
deve ao fato de que os governos nacionais constituem a principal instituição decisória, o Conselho de Ministros, que tem um caráter muito mais intergovernamental do que as demais instituições, sendo, por conseguinte, o ator que mais delega poderes (FRANCHINO, 2004). De fato, a consideração dessas duas lógicas em separado não apenas é algo simplista, mas principalmente se torna uma percepção incompleta. Portanto, segue-se uma análise de como ocorre a delegação nas principais instituições supranacionais; porém, sempre estabelecendo um eixo contextual entre a cessão de poderes da esfera nacional para a supranacional e do próprio corpo institucional.

\section{A Comissão Executiva}

A Comissão é considerada a instituição mais supranacional ${ }^{11}$ do sistema europeu e tem sido o principal objeto de pesquisa daqueles que utilizam o paradigma principal-agente no estudo da União Europeia. Esse órgão é constituído por representantes indicados pelos governos nacionais, estando seu presidente e membros sujeitos à aprovação pela maioria absoluta do Parlamento e pela maioria qualificada do Conselho. Seus membros geralmente são oriundos de cargos públicos, em grande parte com mandatos proporcionais, e têm alguma área de atuação em especial, como, por exemplo, agricultura, comércio, meio ambiente, entre outros, sendo seus mandatos de cinco anos. A Comissão tem como principais funções, com base nos indicativos do Conselho, elaborar as proposições a serem discutidas, bem como implementar parte daquelas que forem adotadas e colaborar nos diversos processos decisórios existentes. ${ }^{12}$

Dentro da abordagem de Pollack (1999), podemos então enquadrar a Comissão em três das quatro perspectivas de delegação: monitoramento; promoção da credibilidade do sistema; e poder de agenda. Segundo o autor, a primeira se daria pelo fato de a Comissão ser considerada a "guardiã dos tratados" (POLLACK, 1999, p. 7), no que tange à observação e suporte na aplicação das normas comunitá- 
rias, mesmo antes da interferência da Corte de Justiça. A segunda ocorre, idealmente, pela expertise e tecnicidade das matérias discutidas, sendo papel do órgão construir uma proposição concisa, mas com um conteúdo que ofereça vantagens a todos os membros; além disso, o órgão deve assessorar o Conselho no processo decisório ao fornecer propostas alternativas à original. Em relação ao poder de agenda, este é relativo e depende do tipo de processo decisório adotado. Segundo Pollack (1999), o poder de agenda da Comissão aumentou de forma significativa com o Tratado de Amsterdã, ratificado em 1997, ampliando sua área de atuação no primeiro e segundo pilares, a saber o comunitário e o de política externa e segurança comum. No entanto, o autor faz algumas ressalvas: "Entretanto, o grau de poder de agenda delegado para a Comissão varia sua forma dependendo da sensibilidade do assunto, e a proliferação de novas fórmulas reflete o interesse em limitar a autonomia da Comissão nessas áreas sensíveis" (POLLACK, 1999, p. 8).

Em grande parte da literatura pesquisada, foi possível identificar um maior número de artigos preocupados em perceber em que momentos a Comissão detém maior poder de agenda e em quais esse poder é constrangido. Tsebelis e Garret (1996) dedicaram-se a analisar em que matérias a Comissão tem maior poder de iniciativa e em quais ela é mais autônoma para elaborar uma proposta a ser apreciada pelo Conselho. Para tanto, fizeram inferências sobre os tipos de decisão existentes no sistema institucional europeu a fim de constatar em qual deles a Comissão exerce mais poder de barganha. Os autores afirmam que, em decisões em que a Comissão elabora a proposta e o Conselho delibera por unanimidade, aquela não tem qualquer poder de agenda, pois a matéria precisa ser o mais geral possível para que nenhum dos Estados-membros a vete, diferentemente da maioria qualificada, em que a Comissão necessita apenas do apoio dos países centrais. Dentre as modalidades decisórias, a saber, consulta, cooperação e codecisão, é na cooperação que a Comissão detém maior po- 
der de agenda, pois as modificações feitas pelo Parlamento precisam ser aprovadas por ela para que, então, o Conselho as analise. Isso não acontece durante a codecisão, pois a proposta só irá retornar em uma terceira leitura, quando o Comitê de Conciliação é constituído pelas três instituições, Conselho, Comissão e Parlamento.

Em um artigo mais recente, essa percepção foi corroborada por Franchino (2004), que afirma, ainda, que a regra da unanimidade em algumas matérias é mantida por causa do teor controverso de alguns assuntos, em que os governos membros tendem a limitar os poderes de implementação e monitoramento delegados à Comissão. O aumento do escopo de atos deliberados por maioria qualificada traduziria uma maior afinidade entre as preferências da Comissão e dos Estados-membros, representados no Conselho.

Isso nos leva a uma outra discussão recentemente levantada por alguns autores: a indicação dos membros da Comissão Executiva. Como foi visto anteriormente, na teoria da delegação, a escolha de um agente que tenha preferências próximas às do principal é um dos mecanismos de controle para que a tarefa delegada seja executada. Um dos primeiros pesquisadores a se dedicarem a essa temática desafiou a afirmação de que a Comissão é o ente mais integracionista da União Europeia. Segundo Crombez (apud MAJONE, 2001), as preferências dos comissários europeus são diretamente constrangidas pelas preferências dos governos nacionais, tendo em vista que, apesar de os comissários não serem demitidos sem que haja um pedido do Conselho ou da própria Comissão, a sua escolha ainda é uma tarefa dos governos nacionais.

Porém, essa percepção está longe de ser um consenso. Tsebelis e Garret (2000) afirmam que, para um governo nacional, é preferível indicar um comissário independente e pró-integração, e que, por consequência, tenha maior poder de barganha com outros países, do que um comissário notoriamente particularista no que tange ao interesse 


\section{Delegação e Integração Regional: Aspectos}

Teóricos do Paradigma Principal-Agente...

da comunidade, adquirindo menos prestígio e influência dentro da Comissão. Segundo Majone (2001, p. 112), ambas as perspectivas têm o seu mérito, porém:

Elas perdem o que é discutivelmente o mais importante fator para a indicação dos comissários: o desejo dos governos nacionais de promover seu comprometimento para a integração europeia. [...] se as preferências dos comissários simplesmente refletissem as preferências dos governos que os apontam, então não haveria distinção funcional significante entre Comissão e Conselho.

Contudo, a posição de Majone (2001) vai além das preferências dos comissários e dos governantes que os indicam. Ele afirma que a relação existente entre os Estados-membros e a Comissão não se restringe a uma relação entre principal e agente. Segundo ele, existe neste aspecto uma delegação total de competências por parte dos Estados-membros ao indicar um comissário e, mais, em proveito de uma terceira pessoa, a comunidade europeia como um todo. Dentro dessa percepção, Majone (2001) estabelece a relação entre os Estados-membros e os comissários como uma relação de confiança; estes últimos, portanto, não seriam agentes, mas fiduciários (trustees) dos governos nacionais. No entanto, o autor mesmo revela que os Estados-membros, atuando individualmente no Conselho de Ministros, determinam as condições sob as quais a Comissão Executiva implementa os atos que o próprio Conselho delibera: "Em suma, a Comissão é um agente quando exerce seus poderes de implementação, delegados pelo Conselho, mas é um fiduciário dos Estados-membros quando exerce outros poderes mencionados acima" (MAJONE, 2001, p. 114-115).

Segundo pesquisa desenvolvida por Hug (2003, p. 59), em que o autor averigua o posicionamento dos comissários na ratificação do Tratado de Amsterdã, em 1997, em apenas dois assuntos a Comissão de- 
sempenhou um papel mais próximo aos governos nacionais, a saber, meio ambiente e emprego. Nos demais 78 assuntos, as propostas elaboradas não correspondiam a um Pareto definido pelos Estadosmembros, apesar de não estarem muito afastadas dele. Entretanto, ele afirma ser difícil estabelecer as causas para essa ocorrência; faz-se necessário que as pesquisas se estendam nesse campo e acumulem mais material empírico, tendo em vista uma lógica temporal de acompanhamento e análise.

Como é perceptível, a maior parte das pesquisas que envolvem o paradigma principal-agente se concentram no desempenho da Comissão e da sua relação com o Conselho de Ministros. Porém, é válido dar um pouco de atenção a duas outras instituições recentemente citadas nos trabalhos sobre delegação e União Europeia, a saber, o Parlamento e a Corte de Justiça.

\section{O Parlamento Europeu}

Dentre as instituições supranacionais discutidas neste artigo, o Parlamento Europeu é o único composto por representantes eleitos diretamente pelos cidadãos europeus, ao contrário da Comissão Executiva e da Corte de Justiça, cujos membros são indicados pelos governos nacionais. Desde 1979, os cidadãos europeus podem eleger seus representantes por sufrágio universal, de acordo com o sistema eleitoral interno de cada país, sendo o mandato de cinco anos. Uma característica importante do Parlamento é a tendência de seus integrantes votarem de acordo com afinidades ideológicas extranacionais, em que um posicionamento entre esquerda e direita é muito mais evidente do que pró ou contra a integração, inclusive contrariando o direcionamento de suas bases nacionais (FOLLESDAL; HIX, 2006).

As principais pesquisas têm concentrado suas análises na crescente delegação de autoridade ao Parlamento no processo decisório europeu (HUG, 2003). Segundo Pollack (1999), o Parlamento fora um 
dos poucos vencedores do Tratado de Amsterdã (1997), principalmente no que diz respeito à extensão do procedimento de codecisão, sendo expandida sua aplicabilidade para 23 novas matérias e outras já existentes, incluindo saúde pública, meio ambiente, mercado interno e outros. Além disso, na ratificação do Tratado, o Conselho assumiu o compromisso de, em cinco anos, estender a codecisão para áreas comunitárias, como alguns assuntos sobre asilo e imigração (POLLACK, 1999, p. 9). Um outro ponto positivo do Tratado para o Parlamento foi a possibilidade de este participar da aprovação do presidente da Comissão, e não apenas o corpo da Comissão, como era antes com o Tratado de Maastricht, ratificado em 1992. Porém, Pollack (1999) aponta causas ideológicas para a delegação de poderes ao Parlamento por meio da codecisão, tendo em vista que matérias sensíveis continuam sendo deliberadas por meio da consulta ou cooperação, em que o Parlamento não detém poder de agenda, como, por exemplo, novas cláusulas, grande parte das proposições sobre asilo e imigração, flexibilidade dos arranjos no primeiro pilar e em todo o terceiro pilar, que trata da cooperação política e judicial.

[...] os Estados-membros estavam claramente motivados primeiramente pela ideologia democrática na sua decisão para delegar novos poderes para o Parlamento em Amsterdã; ainda aqui Estados-membros são cautelosos em calcular as prováveis consequências da delegação, e retêm poderes adicionais, em que o esperado é que o Parlamento seja mais ativo que o Conselho (POLLACK, 1999, p. 10).

Porém, Tsebelis e Garret (1996) têm uma posição mais cética ainda do que a de Pollack. Ao analisarem o poder de agenda das instituições envolvidas no processo deliberativo por cada tipo de procedimento, eles discordam da afirmação de que, durante a codecisão, o Parlamento Europeu adquire paridade decisória junto ao Conselho. Segundo os autores, ao deter poder de veto sobre as propostas do 
Conselho, o Parlamento prejudica a sua habilidade de interferir na agenda do Conselho, pois o veto por si só não permite que a matéria seja emendada, mas possibilita que seja simplesmente paralisada por completo. Isso não apenas torna o ritmo integracionista mais lento, como inibe o Parlamento a vetar a proposição em discussão, tornando inócuo esse mecanismo. Porém, os próprios autores reconhecem que a ausência de pesquisas na área e de material empírico disponível sobre o processo não permite que tal perspectiva seja colocada à prova (TSEBELIS; GARRET, 1996, p. 357).

\section{A Corte de Justiça}

A Corte de Justiça é formada por juízes e advogados gerais nomeados em comum acordo pelos Estados-membros, cumprindo um mandato de seis anos, sendo que, a cada três, pode-se substituir parcialmente seus membros ou renovar a sua permanência para os três anos restantes. Dentre suas funções, as principais são de solução de controvérsias, interpretando cláusulas incompletas das leis comunitárias primárias e secundárias, bem como arbitrando disputas entre Estados-membros, organizações supranacionais e cidadãos privados que se sintam lesados de alguma forma pela lei comunitária. Segundo Pollack (1999), a delegação de poderes para a Corte de Justiça é mais intensa em assuntos relacionados ao pilar comunitário. Sua participação no terceiro pilar, o de cooperação policial e judicial, ainda é tímida, tendo sua jurisprudência limitada para interpretar cláusulas dos tratados. Assim como acontece com a Comissão em determinadas matérias, o alcance da Corte de Justiça no que se refere ao terceiro pilar depende da sensibilidade do assunto em questão.

Os poucos estudos que se dedicaram a aplicar o paradigma principal-agente à relação entre a Corte de Justiça e os Estados-membros da União Europeia apresentaram, como suas primeiras conclusões, o fato de que a Corte de Justiça não seria tão imparcial quanto deveria ser, e que por vezes suas decisões favorecem determinados governos 
nacionais com maior poder de influência (GARRET, 1992 apud POLLACK, 2006). Meunier e Nicolaïdis (1999) são incisivos ao afirmarem que o comportamento da Corte de Justiça busca aceitação política, pois haveria uma linha muito tênue, na interpretação da lei, entre uma posição integracionista baseada na teologia natural do tratado e uma posição mais cautelosa em "respeito aos clamores legítimos de alguns Estados-membros por jurisdição soberana" (MEUNIER; NICOLAÏDIS, 1999, p. 492).

De fato, são afirmações fortes e que necessitam de mais pesquisa e dados empíricos para corroborá-las ou não. Segundo Pollack (2006), aos poucos, têm surgido estudos baseados em modelos da escolha racional que têm enfatizado a complexidade existente nas relações entre a Corte de Justiça, as cortes nacionais e a própria natureza das leis comunitárias. No entanto, alguns problemas no emprego do paradigma principal-agente no estudo da delegação internacional merecem uma discussão mais pragmática.

\section{As Dificuldades na Aplicação do Paradigma Principal-Agente}

Os problemas explorados nesta última parte do artigo se concentram na aplicabilidade do paradigma a sistemas integrados, tendo como exemplo a União Europeia. No entanto, é perceptível que algumas dessas dificuldades se referem não apenas ao objeto de pesquisa do artigo, mas à própria teoria da escolha racional, da qual o paradigma estudado faz parte. Dentro da literatura utilizada neste trabalho, identificam-se duas ordens principais de discussão sobre as limitações do paradigma: conceituais e metodológicas.

Ao introduzir a noção de binding authority, Bradley e Kelley (2006) afirmam não ser um ato de delegação aquele em que um Estado-membro detém controle ${ }^{13}$ sobre o organismo ao qual atribuiu 
competências. Segundo os autores, a noção de delegação internacional é comumente distorcida, principalmente se o órgão em questão for coletivo, com vários países fazendo parte dele. Os autores inclusive não utilizam o termo "agente", mas sim a palavra "entidade" para definir o organismo responsável pelas tarefas delegadas. Dessa forma, Bradley e Kelley (2006) estabelecem uma diferença significativa entre a delegação de poderes exercida na esfera nacional e na internacional, mas ao mesmo tempo restringem a aplicação da teoria da delegação ao plano doméstico, pois para a mesma existir no cenário externo necessitaria de uma delegação total de autoridade por parte dos membros dessa entidade, configurando-se também como irreversível e intransponível. Essas características são improváveis de serem estabelecidas empiricamente, pois até mesmo em organismos como a ONU há a possibilidade de alguns membros inviabilizarem uma decisão que os prejudiquem, principalmente no Conselho de Segurança, por exemplo.

Majone (2001), de certa forma, forneceu os argumentos para a perspectiva de Bradley e Kelley (2006). Na medida em que identificou duas lógicas de delegação, estabeleceu que a relação existente entre os Estados-membros e o sistema institucional europeu é uma delegação total de autoridade. Isso se daria em virtude da necessidade de forjar mais credibilidade e, por consequência, mais resultados próximos a um Pareto eficiente, em que nenhum de seus membros perderia com a associação econômica. Dessa forma, o autor não considera as instituições supranacionais como um agente dos Estados-membros, mas como um fiduciário (trustee) - percepção semelhante ao conceito de binding authority -, sobre cujas ações os Estados-membros não deteriam qualquer poder de controle. Porém, ao reconhecer que os Estados-membros, agindo no Conselho Europeu, determinam e decidem sobre as funções das instituições supranacionais, à exceção do Parlamento Europeu, Majone (2001) afirma que a relação principal-agente existiria. 
Ao que parece, estabelecer conceitualmente quais relações institucionais na União Europeia são de delegação e quais são os agentes e principais é uma tarefa teórica ainda não superada e bastante controversa. Em resposta às afirmações sobre que nomenclatura utilizar para cada ato de delegação no âmbito europeu, Tierney (2006, p. 4) é incisivo:

Eu não posso pensar em uma razão conceitual para mudar os nomes desses atores em uma relação de delegação. Nós não ganhamos nada nomeando agentes de entidades ou fiduciários ou qualquer outro termo vasto ou limitado. Se eles têm condicionalmente autoridade delegada por algum outro ator, então eles são agentes por definição. Se eles fazem exatamente o que o principal quer que eles façam com a autoridade delegada, eles ainda são um agente. Se eles não fazem nada do que o principal quer que eles façam com a autoridade delegada, eles ainda são um agente. Esse tipo de variação em um comportamento do agente deveria ser explicado mais do que usado como uma oportunidade para proliferar novos nomes para conceitos existentes.

Apesar das afirmações de Tierney (2006) serem ríspidas, elas devem ser consideradas, tendo em vista o ainda incipiente caráter dos estudos que aplicam o paradigma ao sistema europeu. ${ }^{14}$ No entanto, essa proliferação de termos a que se refere o autor denota um reflexo da mais comum crítica metodológica feita ao paradigma: a dificuldade em se comprovar suas afirmações empiricamente. Segundo Pollack et al. (2006), há várias críticas contundentes à teoria da escolha racional, porém existe uma interface entre todas elas no que se refere à falta de precisão empírica e ao clamor da teoria em buscar evidências que confirmem as hipóteses preestabelecidas pelo modelo. Os principais críticos, grande parte deles oriundos da escola construtivista, afirmam que a escolha racional não consegue apreen- 
der as mudanças nas preferências dos atores, tampouco como as preferências são formadas; elas são dadas apenas como um fato e a partir delas as hipóteses são construídas.

Simon Hug (2003, p. 42) desafia essas informações e afirma ser não apenas possível, mas em certa medida fácil, identificar-se as preferências dos atores. Segundo ele, existe um erro de interpretação dos críticos da escolha racional, pois o que é improvável de se apreender é a preferência de um ator em nível individual. Todavia, em uma perspectiva institucionalista, tanto a preferência endógena quanto a mudança da mesma são identificáveis. Ainda conforme o autor, embora a escolha racional trabalhe a princípio com preferências fixas, novas informações e mudanças no contexto da ação podem acarretar em um ranking de preferências que guia para a mudança das mesmas, porém a preferência hipotética fixada inicialmente permanece. Dessa forma, também é papel do institucionalismo da escolha racional definir se a mudança de preferências ocorreu e quais suas causas. ${ }^{15}$ Como exemplo, o autor dedica-se ao estudo da atuação da Comissão Executiva Europeia, por meio da indicação dos comissários feita pelos Estados-membros, estabelecendo duas possibilidades de preferência para indicação: uma política mais integracionista ou não. É interessante observar que o próprio autor conclui que, para explicar o porquê de um Estado-membro adotar uma posição mais integracionista ou não ao apontar o comissário, são necessários um suporte de dados empíricos e observação ao longo do tempo. ${ }^{16}$

Pollack (2006) concorda com as críticas que denominam a escolha racional como uma teoria limitada, mas afirma que essa dificuldade não é exclusiva dessa abordagem e, mais, que a teoria da escolha racional deve ser considerada uma metateoria. Por isso, é verdade que a escolha racional não pode oferecer uma teoria completa sobre política monetária ou judicial, por exemplo, e que uma teoria que se comprometa com essa explicação deve ir além do paradigma principal-agente (POLLACK, 2006, p. 5). No entanto, apesar de limitado, 
o paradigma proposto para discussão deste artigo tem contribuído de forma significativa para se entender o funcionamento das instituições e os possíveis comportamentos adotados nas relações sociais, como também tem provido a ciência política de um instrumental teórico interessante e pragmático que outras abordagens não atingem ou não estabelecem como foco.

Abaixo, temos uma tabela que sintetiza as perspectivas abordadas pelo artigo e indica os argumentos dos principais atores:

\section{Tabela 2*}

Síntese das Relações de Delegação na União Europeia

\begin{tabular}{|c|c|c|}
\hline Autores & Relação Delegativa na UE & $\begin{array}{l}\text { Argumentos da } \\
\text { Delegação }\end{array}$ \\
\hline Tsebelis e Garret (1996) & $\begin{array}{l}\text { Comissão e } \\
\text { Parlamento - Agentes } \\
\text { Conselho - Principal }\end{array}$ & $\begin{array}{l}\text { Poder delegado de agenda } \\
\text { varia de acordo com o } \\
\text { sistema decisório adotado. }\end{array}$ \\
\hline Pollack (1999) & $\begin{array}{l}\text { Comissão, Corte de Justiça } \\
\text { e Parlamento - Agentes } \\
\text { Conselho - Principal }\end{array}$ & $\begin{array}{l}\text { Monitoramento; solução de } \\
\text { controvérsias; poder de } \\
\text { agenda; poder de iniciativa. }\end{array}$ \\
\hline Majone (2001) & $\begin{array}{l}\text { Comissão - Trustee dos } \\
\text { Estados-membros; } \\
\text { Comissão - Agente do } \\
\text { Conselho }\end{array}$ & $\begin{array}{l}\text { Políticas de } \\
\text { comprometimento; } \\
\text { redução dos custos na } \\
\text { tomada de decisão. }\end{array}$ \\
\hline Franchino (2004) & $\begin{array}{l}\text { Comissão - Agente } \\
\text { Conselho - Principal }\end{array}$ & $\begin{array}{l}\text { Conselho apenas delega } \\
\text { poderes de iniciativa à } \\
\text { Comissão em áreas de } \\
\text { maior consenso. }\end{array}$ \\
\hline Bradley e Kelley (2006) & $\begin{array}{l}\text { União Europeia - Entidade } \\
\text { Estados-membros - } \\
\text { Principais }\end{array}$ & $\begin{array}{l}\text { Binding authority - } \\
\text { Delegação total }\end{array}$ \\
\hline Tierney (2006) & $\begin{array}{l}\text { Instituições } \\
\text { supranacionais - Agentes } \\
\text { Conselho/governos } \\
\text { nacionais - Principal } \\
\text { coletivo }\end{array}$ & $\begin{array}{l}\text { Evita a proliferação de } \\
\text { nomes para as diferentes } \\
\text { relações de delegação } \\
\text { existentes e defende o foco } \\
\text { em explicar como elas se } \\
\text { dão. }\end{array}$ \\
\hline
\end{tabular}

* Tabela elaborada pela autora. 


\section{Considerações Finais}

O presente artigo teve como objetivo explorar os estudos sobre delegação e integração regional, discutindo conceitual e metodologicamente como se dá a transposição da esfera de delegação doméstica para a esfera internacional. É evidente que, por ser uma abordagem recente, o paradigma principal-agente aplicado ao sistema institucional europeu apresenta algumas dificuldades e discordâncias entre os pesquisadores da área, porém é uma característica indispensável na construção do conhecimento científico.

É interessante destacar que, mesmo com os problemas enfrentados pelo paradigma, surgem novas perspectivas de análise, inclusive sobre temas até um pouco obscuros para os estudiosos da integração regional. Dentre eles, a indicação dos membros das instituições supranacionais por parte dos governos nacionais, não apenas revelando a necessidade de organismos como o Conselho Europeu disponibilizarem mais informações sobre seu funcionamento interno, mas questionando quais e em que medida as políticas europeias requerem um nível de tecnicidade maior; de que forma as instituições supranacionais agem de acordo com o bem coletivo; como, quando e quanto poder é delegado pelos Estados-membros; e, por fim, de que forma os cidadãos europeus se envolvem nesse processo. Certamente que estas e outras indagações não foram totalmente satisfeitas no artigo em questão, e algumas delas sequer foram abordadas.

Em suma, o arcabouço institucional europeu é deveras complexo e merece atenção. O paradigma principal-agente pode sim ser empregado nesse estudo, apesar de algumas ressalvas identificadas pelo artigo. Porém, essas objeções fazem parte do próprio desenvolvimento da teoria e não podem servir de obstáculos para que a mesma não seja explorada, corroborada ou não. De fato, a teoria da delegação tem mostrado ser capaz de contribuir com o entendimento das relações 
interinstitucionais europeias; no entanto, há ainda um longo caminho a percorrer.

\section{Notas}

1. Com exceção do penúltimo processo de adesão, em que dez países ingressaram no bloco de uma só vez.

2. Esta e as demais citações de originais em língua estrangeira foram livremente traduzidas para este artigo.

3. No sentido aqui empregado por Wilson (1989), principals podem ser também ministros, governantes locais e estaduais, e não apenas o governo executivo nacional.

4. O termo mais apropriado seria "empréstimo", pois soberania não é totalmente cedida - é, no máximo, compartilhada. Para mais informações sobre o termo, ver Dougherty e Pfaltzgraff Jr. (2001).

5. Na literatura sobre delegação internacional de aspecto mais normativo, é comum a substituição do termo agente por entidade ou organização, pois alguns autores consideram esses últimos mais abrangentes.

6. Nesse caso, segundo os autores, a constituição da ONU não poderia ser considerada uma relação de delegação, mas uma relação de compromisso entre seus membros.

7. Segundo o art. $3^{\circ}-B$ do Tratado da União Europeia: "Nos domínios que não sejam das suas atribuições exclusivas, a Comunidade intervém apenas, de acordo com o princípio da subsidiariedade, se e na medida em que os objetivos da ação encarada não possam ser suficientemente realizados pelos Estados-membros, e possam pois, devido à dimensão ou aos efeitos da ação prevista, ser mais bem alcançados ao nível comunitário" (TRATADO..., 1992).

8. Delegação de uma esfera nacional para uma supranacional.

9. Noção de binding authority.

10. Sendo assim, organizações como a $\mathrm{ONU}$ e a $\mathrm{OMC}$ não se enquadrariam nessa perspectiva. Mesmo tendo a autoridade para adotar políticas que possam não beneficiar alguns de seus membros, essas organizações não seriam um 
exemplo de pooling sovereignthy, pois alguns de seus membros têm poder de veto e fórum privilegiado.

11. Segundo o Tratado da União Europeia (1992), em seu art. 213 , a Comissão tem um caráter de "total independência no interesse geral da Comunidade".

12. São eles: decisão por consulta, em que o Conselho delibera sem a intervenção do Parlamento, apesar de este ser consultado sobre a matéria; decisão por cooperação, em que o Conselho, para emitir uma decisão, necessita primeiro analisar sugestões ali contidas; e codecisão, em que, após um processo de leituras da proposição, tanto o Conselho como o Parlamento podem vetar a matéria final, tendo como consequência a manutenção do status quo.

13. É preciso clarificar que controle não se resume apenas a mecanismos punitivos ex-ante e/ou ex-post, mas também a sanções informais e menos diretas, como, por exemplo, a escolha do agente e a possibilidade de sua permanência ou retorno ao cargo, como acontece na Comissão Executiva, em que os Estados-membros apontam seus representantes e, apesar de não poderem demiti-los diretamente após assumirem o cargo, têm a possibilidade de, após cincos do mandato, indicarem um representante com uma postura diferente do anterior, nesse caso mais integracionista ou não (HUG, 2003).

14. Pollack (2006) chega a afirmar que a definição proposta por Majone (2001) é totalmente desnecessária.

15. Essa perspectiva de Hug (2003) nos remete à noção de bounded rationality, ou racionalidade constrangida, que, segundo Melo (1996), permitiu que o institucionalismo da escolha racional pudesse explorar o impacto da incerteza nas transações sociais.

16. Taylor e Hall (2001) apontam para a possibilidade de se combinar os diversos tipos de institucionalismos a fim de se explicar como se dá a interação entre o comportamento humano e as instituições criadas.

\section{Referências Bibliográficas}

BENDOR, Jonathan; GLAZER, Amihai; HAMMOND, Thomas H. Theories of delegation. Annual Review Political Science, v. 4, p. 253-269, 2001. 


\section{Delegação e Integração Regional: Aspectos}

Teóricos do Paradigma Principal-Agente...

BRADLEY, C. A.; KELLEY, J. The concept of international delegation. Trabalho apresentado à Conference on Delegating Sovereighty: Constitutional and Political Perspectives, Duke University, 3-4 mar. 2006. Disponível em: <http:// www.law.duke.edu/publiclaw/workshop/papers.html>. Acesso em: 14 abr. 2007.

D’ARCY, François União Europeia: instituições, políticas e desafios. Rio de Janeiro: Konrad Adenauer, 2002.

DOUGHERTY, James E.; PFALTZGRAFF JR., Robert L. Contending theories of International Relations: a comprehensive survey. United States: Longman, 2001.

EPSTEIN, D.; O'HALLORAN, S. Delegating powers. A transaction cost politics approach to policy making under separate powers. Cambridge: Cambridge University Press, 1999.

Delegation games and sovereighty. Trabalho apresentado à Conference on Delegating Sovereighty: Constitutional and Political Perspectives, Duke University, 3-4 mar. 2006. Disponível em: <http://www.law.duke.edu/ publiclaw/workshop/papers.html>. Acesso em: 14 abr. 2007.

FOLLESDAL, A.; HIX, S. Why there is a democratic deficit in the EU: a response to Majone and Moravcsik. Journal of Common Market Studies, v. 44, n. 3, p. 533-562, 2006.

FRANCHINO, F. Delegating powers in the European Community. British Journal of Political Science, v. 34, n. 2, p. 449-476, 2004.

HUG, S. Endogenous preferences and delegation in European Union. Comparative Political Studies, v. 36, n. 1-2, p. 41-74, 2003.

LAKE, D. A. Delegating divisible sovereignty: some conceptual issues. Trabalho apresentado à Conference on Delegating Sovereighty: Constitutional and Political Perspectives, Duke University, 3-4 mar. 2006. Disponível em: <http:// www.law.duke.edu/publiclaw/workshop/papers.html>. Acesso em: 14 abr. 2007.

LUPIA, Arthur. Delegation of power: agency theory. In: SMELSER, N. J.; BALTES, P. B. (Ed.). International Encyclopedia of Social and Behaviorial Science. v. 5. Oxford, UK: Elsevier Science Limited, 2001. 
MAJONE, Giandomenico. Two logics of delegation: agency and fiduciary relations in EU governance. European Union Politics, v. 2, n. 1, p. 103-122, 2001.

MCCUBBINS, Mathew D; SCHWARTZ, Thomas. Congressional oversight overlooked: police patrols versus fire alarms. American Journal of Political Science, v. 28, n. 1, p. 165-179, 1984.

MELO, Marcus A. Governance e reforma do Estado: o paradigma agente x principal. Revista do Servidor Público, v. 120, n. 1, p. 67-79, 1996.

MEUNIER, S.; NICOLAÏDIS, K. Who speaks for Europe? The delegation of trade authority in the EU. Journal of Common Market Studies, v. 37, n. 3, p. 477-501, 1999.

POLLACK, M. A. Delegation, agency and agenda setting in the Treaty of Amsterdam. European Integration Online Papers, v. 3, n. 6, 1999. Disponível em: <http://www.eiop.or.at/texte>. Acesso em: 14 mai. 2007.

Principal-Agent analysis and international delegation: red herrings, theoretical clarifications, and empirical disputes. Trabalho apresentado à Conference on Delegating Sovereighty: Constitutional and Political Perspectives, Duke University, 3-4 mar. 2006. Disponível em: <http://www.law.duke. edu/publiclaw/workshop/papers.html>. Acesso em: 14 abr. 2007.

; JORGENSEN, K. E.; ROSAMOND, B. (Org.). Handbook of European Union Politics. London: SAGE Publications, 2006.

TAYLOR, Rosemary C. R.; HALL, Peter A. As três versões do neo-institucionalismo. Lua Nova, n. 58, p. 193-223, 2001.

TIERNEY, M. J. Delegation of authority in International Relations: the promise and limits of agency theory. Trabalho apresentado à Conference on Delegating Sovereighty: Constitutional and Political Perspectives, Duke University, 3-4 mar. 2006. Disponível em: <http://www.law.duke.edu/publiclaw/workshop/ papers.html>. Acesso em: 14 abr. 2007.

TOSTES, Ana Paula B. União Européia: o poder político do direito. Rio de Janeiro: Renovar, 2004.

TRATADO da União Européia. Jornal Oficial, n. C 191, 29 jul. 1992. Disponível em: <http://eur-lex.europa.eu/pt/treaties/dat/11992M/htm/11992M.html>. Acesso em: 13 mai. 2009. 
Delegação e Integração Regional: Aspectos Teóricos do Paradigma Principal-Agente...

TSEBELIS, G.; GARRET, G. Agenda setting power, power indices, and decision making in the Europe Union. International Review of Law and Economics, v. 16, n. 4, p. 345-361, 1996.

Legislative politics in the European Union. European Union Politics, v. 1, n. 1, p. 9-36, 2000.

WILSON, James Q. Bureaucracy. New York: Basic Book, 1989.

\section{Resumo}

\section{Delegação e Integração Regional: Aspectos Teóricos do Paradigma Principal-Agente Aplicado ao Sistema Europeu}

A aplicabilidade do paradigma principal-agente no estudo das relações institucionais dentro da União Europeia tem despertado o interesse de cientistas políticos e especialistas da área de Relações Internacionais, mais notadamente na última década. É objetivo deste artigo apresentar os principais autores que se utilizam desse paradigma para entender como funciona o sistema europeu, bem como perceber que questões emergem dessa discussão. Dentre as lógicas de delegação mais pesquisadas, destaca-se a atuação da Comissão Europeia, seguida pelo Parlamento Europeu e, de forma mais incipiente, a Corte de Justiça. Todos são considerados agentes dos Estados-membros, representados pelo Conselho Europeu. É dedicado também um espaço para expor as dificuldades teóricas do paradigma, principalmente no que diz respeito à sua comprovação empírica.

Palavras-chave: Delegação - União Europeia - Instituições - Processo Decisório 


\section{Abstract}

\section{Delegation and Regional Integration: Theoretical Aspects of Paradigm Principal-Agent Applied to European System}

The applicability of paradigm principal-agent in European Union studies have been the focus of political scientists and other specialists at International Relations, mostly in last decade. The main goal here is discuss the main theorists who apply this paradigm to understand how works the European system, as well in perceive which questions emerges from this debate. Between the most researched logics of delegation, there is a great interest in the performance of European Commission, European Parliament and Court of Justice, this last one more incipient. All of them are considered as agents of member states, represented by the European Council. It will be also discussed the theoretical difficulties of this paradigm, especially with regard to its empirical evidence.

Keywords: Delegation - Europe Union - Institutions - Decision-making 